\title{
Clinical Pathways in Neuro-Ophthalmology
}

\author{
Eugen Boltshauser ${ }^{1}$ \\ ${ }^{1}$ Department of Pediatric Neurology, University Children's Hospital, \\ Zurich, Switzerland \\ Neuropediatrics 2019;50:208.
}

Stacy V. Smith, Andrew G. Lee, Paul W. Brazis. Clinical Pathways in Neuro-Ophthalmology. An Evidence-Based Approach. New York: Thieme Medical Publishers; 2019 (300 pages). ISBN 978-1-62623-285-3. EUR ca 130.00 (e-book: eISBN 978-1-62623-285-0)

The second edition of this oeuvre dates from 2003 (Lee AG and Brazis PW, eds.). The third edition is edited by a "triumvirate," the two former editors and the neurology-trained neuro-ophthalmologist Stacy Smith, all distinguished neuroophthalmology experts (from Houston, Texas, and Jacksonville, Florida, U.S.A.), supported by 20 additional contributors. In this edition, they classify the clinical evidence into four categories and they grade the strength of the recommendations from each section into four levels.

The volume contains 20 chapters. Some of them deal with topics almost exclusively seen in adults (e.g., arteritic and nonarteritic ischemic optic neuropathy, Graves's ophthalmopathy), while many others are also relevant for the pediatric
Address for correspondence Prof. em. Eugen Boltshauser, Department of Pediatric Neurology, University Children's Hospital, Steinwiesstrasse 75, 8032 Zürich, Switzerland (e-mail: eugen.boltshauser@bluewin.ch).

and adolescent age (e.g., optic neuritis, papilledema, diplopia, nerve palsies, ocular myasthenia gravis, ptosis, nystagmus, transient visual loss, supranuclear disorders of gaze).

All chapters are well structured, with abstract, key words, paragraphs on definitions (if applicable), diagnostic evaluation, clinical features, investigations, and treatment, and they are extensively referenced. Neuroimaging illustrations and fundus photographs are not included, but a large number of evaluation algorithms are presented. All chapters incorporate clearly laid out "boxes" with definitions, etiologies, clinical findings, differential diagnosis, complications et cetera.

Neuro-ophthalmology is a closely related field to pediatric neurology. Pediatric neurologist with a deepened interest in this area will find detailed interesting and stimulating information in this volume.

The printing and the binding are of best quality. The costperformance ratio is fair. (c) 2019 Georg Thieme Verlag KG Stuttgart · New York
DOI https://doi.org/ 10.1055/s-0039-1684005. ISSN 0174-304X. 